\title{
Photocatalytic Protection of Building Materials in Real Environmental Conditions
}

Jonjaua Ranogajec ${ }^{1}$, Snežana Vučetić ${ }^{1}$, John Milan van der Bergh ${ }^{1}$, Bojan Miljević ${ }^{1}$, Helena Hiršenberger $^{2}$

1. University of Novi Sad - Faculty of Technology, Laboratory for Materials in Cultural Heritage, Novi Sad, Serbia.

2. University of Novi Sad - Faculty of Technical Sciences, Department of Industrial Engineering and Engineering Management, Novi Sad, Serbia.

Historical building materials are generally very sensitive to organic, inorganic and microbiological contamination, leading to changes of their aesthetics, structure and durability. New technologies of selfcleaning materials based on photocatalytic effect are promising sustainable approach in protection of immovable cultural heritage. One of solutions for reduction or prevention of decay is to minimize the surface changes by applying protective materials with added values and targeted properties. These materials take an active role in the maintenance of immovable cultural heritage as an effective active protection tool. Different types of functional coatings have been developed until now. A particular problem of their applicability is the absence of their compatibility with the surface of the building materials. This difficulty could be solved by choosing layered double hydroxides (LDHs), highly compatible with mineral substrates, as support for nano-particles of a photocatalyst [1].

The aim of this paper is the application and efficiency examination of the protective coating developed under the European Commission funded FP7 project HEROMAT in real environmental conditions [2]. The protective coating is a nanocomposite based on anionic clay minerals (layered double hydroxides LDHs) with incorporated $\mathrm{TiO}_{2}$ photocatalyst [3]. The LDH was chosen as support material aiming to prevent aggregation of nanoparticles and to provide compatibility with the selected mineral substrates. The protective coating studied in this work and applied on mineral substrates (brick, mortar, render, sandstone, façade paint), has already proven as a functional material with self-cleaning properties in laboratory [1]. The study of developed coating performance in real environmental conditions was conducted on: newly built experimental wall (Serbia), $18^{\text {th }}$ century Austro-Hungarian fortification Petrovaradin Fortress (Serbia) and Dornava Manor from the late Baroque period (Slovenia).

Before the application of the developed coating a detailed examination of the constitutive materials of the selected objects was performed: experimental wall - modern mortars and façade paints; Petrovaradin Fortress - carbonate bricks and historical render; and Dornava Manor - historical calcitic stone. Examination of the constitutive materials was performed by X-Ray Diffraction Analysis, Hg Intrusion Porosimetry, Differential Thermal Analysis/Thermogravimetry, and Scanning Electron Microscopy/Energy Dispersive Spectrometry.

In the case of modern newly built experimental wall, a commercial type of façade paint was used for covering the surfaces [4]. The white painted façade was divided in eight areas and coated with either biocides or newly developed photocatalytic coating. The microorganisms, isolated from the vicinity of the experimental wall, were applied as the contaminants. Diffuse Reflectance Infrared Fourier Transform Spectroscopy (DRIFTS) and visual inspection were used for monthly in situ monitoring of the microbial growth. In the case of historic buildings, the photocatalytic coating was applied to the selected segments: the tunnel walls of the Petrovaradin Fortress (Figure 1a and 1b) and the fountain at 
the Dornava Manor (Figure 1c). The efficiency of the applied photocatalytic coating for organic and microbial degradation was monitored in situ visually and by microscopy analysis. After 3 years following the coating application the obtained results were promising concerning its activity and durability in real environmental conditions (Figure 2).

This paper emphasizes the need for a long term monitoring of new functional materials in real environmental conditions in order to obtain measurable and valid results. Based on the obtained promising results, the developed coating was also used for protection of fresh modern murals. Monitoring of the coating efficiency on wall murals, especially in regard to painted layers and pigments of different nature (organic and inorganic) is regularly performed and the obtained results will be published after 3 years of application [3,5].

References:

[1] O. Rudić et al, Ceramics International 40 (2014), pp. 9445.

[2] Available at www.heromat.com [accessed: 01/15/2018].

[3] T. Vulić et al, Cement and concrete composites 58 (2015), pp. 50.

[4] S. Vučetić et al, Environmental Science and Pollution Research 21 (2014), pp. 11228.

[5] Financial support from the Serbian Ministry of Education, Science and Technological Development (Contract No. III45008) is gratefully acknowledged.
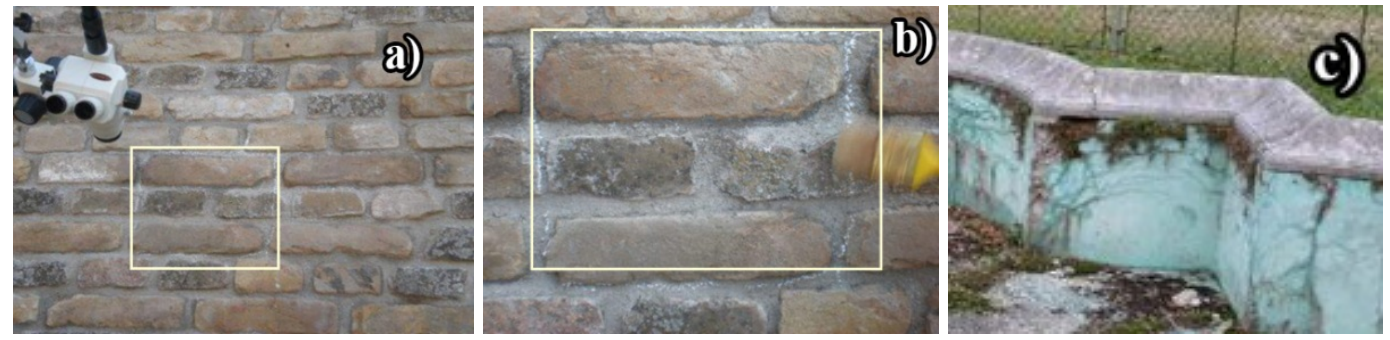

Figure 1. a) Tunnel of the Petrovaradin Fortress before the suspension application; b) Tunnel of the Petrovaradin Fortress immediately after the suspension application; c) Dornava Manor fountain before application
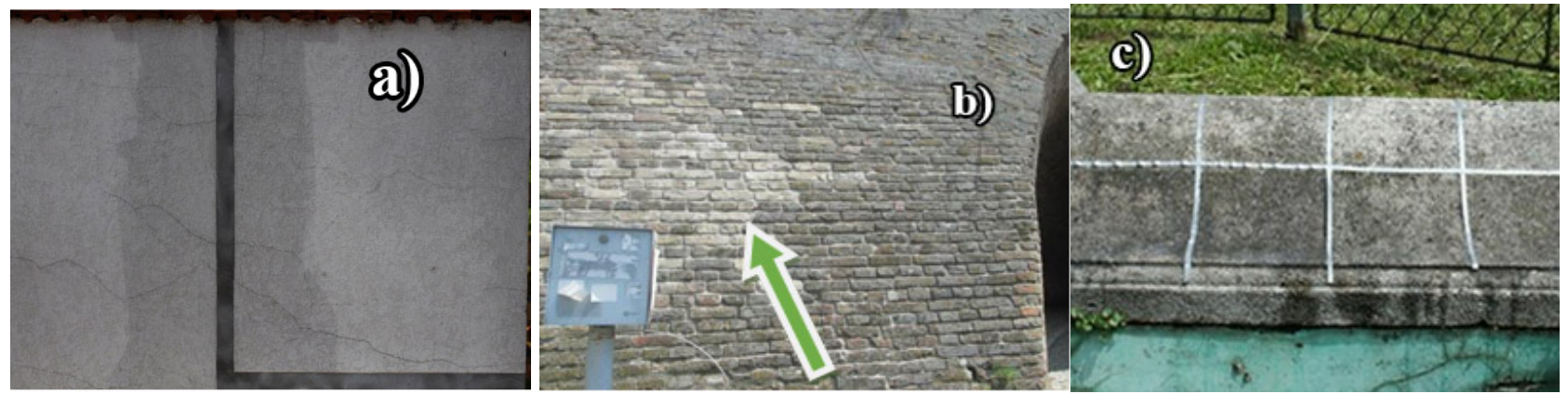

Figure 2. Condition 3 years after the application of coating on: a) experimental wall; b) Petrovaradin fortress; c) Dornava Manor 